\title{
Decomposing ability of diverse litter-decomposer macrofungi in subtropical, temperate, and subalpine forests
}

\author{
$\operatorname{AUTHOR}(\mathrm{S})$ : \\ Osono, Takashi
}

\section{CITATION:}

Osono, Takashi. Decomposing ability of diverse litter-decomposer macrofungi in subtropical, temperate, and subalpine forests. Journal of Forest Research 2014, 20 (2): 272-280

\section{ISSUE DATE:}

2014-12-16

URL:

http://hdl.handle.net/2433/200207

\section{RIGHT:}

The final publication is available at Springer via http://dx.doi.org/10.1007/s10310-014-0475-9.; The full-text file will be made open to the public on 16 December 2015 in accordance with publisher's 'Terms and Conditions for SelfArchiving'.; この論文は出版社版でありません。引用の際には出版社版をご確認ご利用ください。; This is not the published version. Please cite only the published version. 
1 Decomposing ability of diverse litter-decomposer macrofungi in subtropical,

2 temperate, and subalpine forests

3

4 Takashi Osono

5

6 T. Osono

7 Center for Ecological Research, Kyoto University, Otsu, Shiga 520-2113 Japan

8 e-mail: tosono@ecology.kyoto-u.ac.jp

10 AbstractAn integrative survey was conducted on the ability of litter-decomposing

11 macrofungi from forests of different climatic regions to decompose litter materials

12 and recalcitrant compounds in the litter under pure culture conditions. A total of

1375 isolates in six families of litter-decomposing macrofungi from subtropical (ST),

14 cool temperate (CT), and subalpine (SA) forests in Japan were tested for their

15 ability to decompose a total of eight litter types that are major substrates for

16 macrofungi at each site. The mass loss of the litter (\% original mass) during

17 incubation for 12 weeks at $20^{\circ} \mathrm{C}$ ranged from $-3.1 \%$ to $54.5 \%$. Macrofungi 
18 originated from forests of different climatic regions exhibited similar decomposing

19 abilities, but the SA isolates caused negligible mass loss of Abies needles, possibly

20 due to inhibitory compounds. Decomposing activity for recalcitrant compounds (as

21 acid unhydrolyzable residues, AUR) was found in many macrofungal isolates. The

22 isolates of Marasmiaceae were generally more able to cause selective

23 decomposition of AUR than those of Mycenaceae and to decompose AUR in partly

24 decomposed materials. The isolates of Xylariaceae had lower ligninolytic activity

25 than those of Basidiomycetes. The AUR mass loss caused by CT isolates was

26 significantly lower in nitrogen-rich beech litter than in its nitrogen-poor

27 counterpart, suggesting a retarding effect of nitrogen on AUR decomposition,

28 which was obvious for Mycenaceae. The effect of fungal family was generally more

29 significant than that of litter type, suggesting that possible changes in the

30 composition of fungal assemblages influence their functioning more than changes

31 in the quality of substrates.

32

33 Keywords Acid unhydrolyzable residue • Climate • Lignin

34 decomposition · Ligninolytic fungi · Selective delignification 


\section{Introduction}

38 Fungi play central roles in decomposition processes of leaf litter because they are

a dominant component of soil biota and are primary decomposers of lignin and

other recalcitrant compounds that often limit the decomposition but which other

41 soil organisms are rarely able to mineralize. Litter-decomposing macrofungi

42 (LDM) are of particular interest in this regard, as they comprise active

43 ligninolytic species in Basidiomycota and Ascomycota (Osono 2007; Lindahl and

44 Boberg 2008; van der Wal et al. 2013). Researchers have investigated the

45 decomposing abilities of LDM with the pure culture test under laboratory

46 conditions, commonly using single litter types inoculated with several (usually

47 less than 10) LDM species associated with them (Miyamoto et al. 2000; Steffen et

48 al. 2007; Valášková et al. 2007; Boberg et al. 2011; Žif̌cáková et al. 2011). To the

49 knowledge of the author, few studies have compared the abilities of diverse LDM

50 to decompose multiple litter types, and compared these abilities among isolates

51 belonging to different taxa and originating from different climatic regions. I 
52 hypothesized that the macrofungal assemblages in warmer climates included a

53 larger number of species that had ligninolytic potential and/or that could

54 selectively decompose recalcitrant compounds than macrofungal assemblages in cooler climates. This was based on casual observations that the decomposition of recalcitrant compounds, such as lignin, is more active in soils at warmer climates

57 (e.g. Hirobe et al. 2004; Osono 2006; Osono et al. 2009).

59 the ability of LDM from forests of different climatic regions to decompose litter

60 materials and recalcitrant compounds in the litter under pure culture conditions.

61 A total of 75 isolates in six families of LDM from subtropical, cool temperate, and

62 subalpine forests in Japan were tested for their ability to decompose a total of

63 eight litter types that were major substrates for LDM at each study site. The

64 contents of acid unhydrolyzable residues were analyzed for litter materials

65 decomposed by LDM to investigate the ability of the LDM to decompose lignin and

66 other recalcitrant compounds in the litter and the degree of selective decomposition of these compounds. These measures were analyzed statistically to 
69 the decomposition by macrofungi from three climatic regions.

70

71 Materials and methods

72

73 Study sites and collection of macrofungi

74

75 Samples were collected from three sites in Japan: a subtropical forest (ST), a cool

76 temperate forest (CT), and a subalpine forest (SA). The location, climatic

77 conditions, vegetation, and properties of the forest floor are described in Osono

78 (2014a, 2014b). Fruiting bodies of litter-decomposing macrofungi (LDM) were

79 collected from the forest floor of the study sites from March 2007 to January 2008

80 in ST, from May to November 2001 in CT, and June to October 2008 in SA (Osono

81 2014b). In the laboratory, mass spores or tissues of fruiting bodies were

82 aseptically plated onto lignocellulose agar (LCA) modified by Miura and Kudo

83 (1970) for isolation. LCA contains glucose $0.1 \%, \mathrm{KH}_{2} \mathrm{PO}_{4} 0.1 \%, \mathrm{MgSO}_{4} \cdot 7 \mathrm{H}_{2} \mathrm{O} 0.02 \%$,

$84 \mathrm{KCl} 0.02 \%, \mathrm{NaNO}_{3} 0.2 \%$, yeast extract $0.02 \%$, and agar $1.3 \%(\mathrm{w} / \mathrm{v})$. Note that the

85 modified LCA described by Miura and Kudo (1970) does not contain lignin or other 
86 recalcitrant compounds. Isolates were maintained on slants of $1 \%$ malt extract

87 agar medium [MEA, malt extract $1 \%$ and agar $2 \%(\mathrm{w} / \mathrm{v})]$ at $20^{\circ} \mathrm{C}$ in darkness until

88 the tests were performed.

89

$90 \quad$ Fungal isolates

91

92 A total of 75 isolates were used in the decomposition test to compare the

93 decomposing ability of multiple fungal species from each study site, including 37

94 isolates from ST, 16 from CT, and 22 from SA (see Electronic Supplementary

95 Material). These fungal isolates from ST, CT, and SA were inoculated to litter

96 types collected from ST, CT, and SA, respectively (denoted as ST, CT, and SA tests).

97 Seventy-one of the 75 isolates were obtained from mass spores or tissues of

98 fruiting bodies during the field survey as described above. One isolate of

99 Marasmius sp.ST3 was isolated from decomposing Castanopsis sieboldii leaves by

100 the surface disinfection method and used for ST tests. The identification of all ST

101 and several SA isolates to species level was not successful (Osono 2014b), and the

102 isolates were analyzed for base sequences of the rDNAs ITS1, 5.8S, ITS2, and 28S 
103 D1/D2 and assigned mostly to genus level by comparing the base sequences with

104 the GenBank database using BLAST (see ESM for the accession numbers in NIAS

105 Genebank). Three isolates (Mycena polygramma IFO33011, Ampulloclitocybe

106 clavipes IFO30524, and Rhodocollybia butyracea IFO30747) were obtained from

107 the culture collection (IFO, Osaka, Japan) and used for CT tests. These three

108 fungal species are commonly encountered in temperate regions (Imazeki and

109 Hongo 1987; Osono 2014b).

110

111 Litter materials

112

113 A total of eight litter types were used as substrata for the decomposition tests,

114 including freshly fallen leaves of seven tree species and one forest floor material.

115 The seven tree species were dominant components of forest stands and major

116 substrates for LDM in each study site (Osono 2014b). Newly shed leaves of

117 Castanopsis sieboldii and Schima wallichii without obvious fungal or faunal

118 attack were collected from the forest floor of ST in March 2008, a peak period of

119 litterfall, and used for ST tests. Newly shed leaves of Fagus crenata and Quercus 
120 crispula without obvious fungal or faunal attack were collected from the forest

121 floor of CT in November 2002, a peak period of litterfall, and used for CT tests.

122 Specifically, leaves of $F$. crenata from the upper and lower parts of the forest slope

123 were collected separately and used for CT tests. These leaves differed in nitrogen

$124(\mathrm{~N})$ content $(1.32 \% \mathrm{w} / \mathrm{w}$ for the upper litter versus $1.75 \%$ for the lower litter),

125 mainly due to soil $\mathrm{N}$ availability and $\mathrm{N}$ use by $F$. crenata (Tateno and Takeda

126 2010). At the same time, partly decayed materials were collected from $\mathrm{F}$ layer at

127 the lower slope and used for CT tests. Hence, four litter types [Fagus (upper),

128 Fagus (lower), Quercus, and partly decomposed material] were used for CT tests.

129 Newly shed leaves of Abies mariesii and Betula ermanii without obvious fungal or

130 faunal attack were collected from the forest floor of SA in October 2008 and used

131 for SA tests. Leaves of broadleaved tree species were cut into strips $1 \mathrm{~cm}$ wide.

132 The leaves were oven-dried at $40^{\circ} \mathrm{C}$ for one week and preserved in vinyl bags until

133 the experiment was started. Tree species used as substrata are referred to as their

134 genus names in the present study for the sake of simplicity.

136 Pure culture decomposition test 
138 An individual pure culture decomposition test consisted of one fungal isolate

139 inoculated to one litter type, making 74 tests (37 isolates $\times 2$ litter types) for ST,

14064 tests $(16$ isolates $\times 4$ litter types) for CT, and 44 tests $(22$ isolates $\times 2$ litter

141 types) for SA. Litters (0.3 g) were sterilized by exposure to ethylene oxide gas at

$14260^{\circ} \mathrm{C}$ for 6 hours and used in the tests according to the methods described in

143 Osono and Hirose (2011). The sterilized litters were placed on the surface of Petri

144 dishes (9-cm diameter) containing $20 \mathrm{ml}$ of $2 \%$ agar. Inocula for each assessment

145 were cut out of the margin of previously inoculated Petri dishes on 1\% MEA with

146 a sterile cork borer (6 $\mathrm{mm}$ diameter) and placed on the agar adjacent to the litters,

147 one plug per plate. The plates were incubated for 12 weeks in the dark at $20^{\circ} \mathrm{C}$.

148 The plates were sealed firmly with laboratory film during incubation so that

149 moisture did not limit decomposition on the agar. After incubation, the litters

150 were retrieved, oven-dried at $40^{\circ} \mathrm{C}$ for 1 week, and weighed. The initial,

151 undecomposed litters were also sterilized, oven-dried at $40^{\circ} \mathrm{C}$ for 1 week, and

152 weighed to determine the original mass. Four plates were prepared for each test,

153 and four uninoculated plates served as a control. Mass loss of litter was 
154 determined as a percentage of the original mass, taking the mass loss of litter in

155 the uninoculated and incubated control treatment into account, and the mean

156 values were calculated for each plate. The original data are listed in ESM. Prior to

157 the tests, the sterilized litters were placed on 1\% MEA, and after 8 weeks of

158 incubation at $20^{\circ} \mathrm{C}$ in darkness, no microbial colonies had developed on the plates.

159 Thus, the effectiveness of the sterilization method used in the present study was

160 verified. The initial litter, the control litter, and the litters with more than or

161 equal to 5.0\% mass loss were used for chemical analyses as described below.

163 Chemical analyses

164

165 Litter materials from four replicate plates were combined to make one sample for

166 each test and ground in a laboratory mill $\left(0.5^{-} \mathrm{mm}\right.$ screen). The amount of

167 acid-unhydrolyzable residue (AUR) in the samples was estimated by means of

168 gravimetry as acid-insoluble residue, using hot sulfuric acid digestion (King and

169 Heath 1967). Samples were extracted with alcohol-benzene at room temperature

$170\left(15-20^{\circ} \mathrm{C}\right)$, and the residue was treated with $72 \%$ sulfuric acid $(\mathrm{v} / \mathrm{v})$ for $2 \mathrm{~h}$ at room 
171 temperature with occasional stirring. The mixture was diluted with distilled

172 water to make a $2.5 \%$ sulfuric acid solution and autoclaved at $120^{\circ} \mathrm{C}$ for $60 \mathrm{~min}$.

173 After cooling, the residue was filtered and washed with water through a porous

174 crucible (G4), dried at $105^{\circ} \mathrm{C}$ and weighed as AUR. This AUR fraction contains a

175 mixture of organic compounds in various proportions, including condensed

176 tannins, phenolic and carboxylic compounds, alkyl compounds such as cutins, and

177 true lignin (Preston et al. 1997).

178

Mass loss of AUR was determined as a percentage of the original mass,

179 taking the mass loss of AUR in the uninoculated and incubated control treatment

180 into account. AUR/litter mass (AUR/L) loss ratio is a useful index of the selective

181 delignification caused by each fungal species (Osono and Hirose 2009). AUR/L loss

182 ratio of each fungal species was calculated according to the equation:

183

AUR/L loss ratio = mass loss of AUR (\% of original AUR mass) $/$ mass loss

184 of litter (\% of original litter mass)

185

$186 \quad$ Statistical analysis 
188 Effects of fungal family, litter type, and the fungal family $\times$ litter type interaction

189 on the mass loss of litter and AUR and AUR/L loss ratio were analyzed with

190 generalized linear models (GLMs) with a Gaussian distribution for each of ST, CT,

191 and SA tests. Only the fungal family was used as an independent variable in the

192 GLMs to test the mass loss of AUR and AUR/L loss ratio for Betula litter in SA

193 tests, because the mass loss of Abies litter was less than $5 \%$ for all fungal isolates

194 tested and no AUR analysis was conducted. The GLMs were performed with the

$195 \mathrm{glm}$ function of $\mathrm{R}$ version 3.0.2 for Mac (http://www.r-project.org) and with the $g l h t$

196 function of the $\mathrm{R}$ multcomp package for multiple comparisons with Tukey's test.

197 Paired t-test was also used to compare the mass loss of litter and AUR and AUR/L

198 loss ratio between Fagus (lower) and Fagus (upper) litter, using JMP 6.0 for 199 Macintosh.

200

$201 \quad$ Results

202

203 Litter mass loss 
205 The mean mass loss of the litter caused by 37 isolates of ST tests ranged from

$2062.3 \%$ to $34.3 \%$ of the original litter mass for Castanopsis litter, and from $-0.4 \%$ to

$20730.3 \%$ for Schima litter; that caused by 16 isolates of CT tests ranged from $4.1 \%$ to

$20830.2 \%$ for Fagus (upper) litter, from 2.3\% to $29.3 \%$ for Fagus (lower) litter, from

$2090.1 \%$ to $42.8 \%$ for Quercus litter, and from $2.9 \%$ to $34.1 \%$ for partly decomposed

210 material; and that caused by 22 isolates of SA tests ranged from $-3.1 \%$ to $0.6 \%$ for

211 Abies litter and from $0.0 \%$ to $54.5 \%$ for Betula litter (Fig. 1). The largest mean

212 mass loss was found for Marasmius androsaceus inoculated to Betula litter in the

213 SA test, whereas all SA isolates caused negligible mass loss of Abies litter.

214 In ST tests, the mass loss of litter was significantly larger for

215 Mycenaceae than for Marasmiaceae (GLM, d.f.=3, deviance=625.0, P<0.05; Table

216 1) and was not significantly different between Castanopsis and Schima litter

217 (GLM, d.f.=1, deviance=135.6, P=0.17; Fig. 1). The effect of fungal family $\times$ litter

218 type interaction was not significant (GLM, d.f.=3, deviance=81.1, $\mathrm{P}=0.77$ ). In CT

219 tests, the mass loss of litter was not significantly different among fungal families

220 (GLM, d.f.=3, deviance=733.7, P=0.08; Table 1), four litter types (GLM, d.f.=3,

221 deviance=548.5, $\mathrm{P}=0.17$; Fig. 1), or the fungal family $\times$ litter type interaction 
222 (GLM, d.f.=9, deviance=973.2, $\mathrm{P}=0.46$ ). When analyzed separately, the mean mass

223 loss caused by the 16 CT isolates was not significantly different between Fagus

224 (upper) and Fagus (lower) litter (paired t-test, d.f.=15, t=0.176, P=0.86),

225 indicating that the initial $\mathrm{N}$ level in litter had no significant effect on fungal

226 decomposition of the whole litter. In SA tests, the mass loss of litter was

227 significantly affected by fungal family (GLM, d.f.=4, deviance=1007.6, $\mathrm{P}<0.05$;

228 Table 1), litter type (GLM, d.f.=1, deviance=4577.5, $\mathrm{P}<0.001$; Fig. 1), and the

229 fungal family $\times$ litter type interaction (GLM, d.f.=4, deviance=1071.5, P<0.05).

230 The mass loss of Betula litter was generally larger for Mycenaceae than for

231 Hymenogasteraceae (Table 1).

232

233 AUR loss

234

235 The mean mass loss of acid-unhydrolyzable residues (AUR) caused by ST isolates

236 ranged from $0.7 \%$ to $62.6 \%$ of the original AUR mass for Castanopsis litter and

237 from $0.5 \%$ to $41.0 \%$ for Schima litter; that caused by CT isolates ranged from

$23820.1 \%$ to $70.5 \%$ for Fagus (upper) litter, from $17.2 \%$ to $64.8 \%$ for Fagus (lower) 
239 litter, from $7.6 \%$ to $69.4 \%$ for Quercus litter, and from $12.7 \%$ to $70.4 \%$ for partly

240 decomposed material; and that caused by SA isolates ranged from $0.2 \%$ to $70.6 \%$

241 for Betula litter (Fig. 2). Abies litters inoculated with SA isolates were not

242 analyzed for AUR loss because the values of mass loss of litter caused by SA

243 isolates were negligible (Fig. 1).

244 In ST tests, the mass loss of AUR was significantly larger for Mycenaceae and Marasmiaceae than for Xylariaceae (GLM, d.f.=3, deviance=2561.0, $\mathrm{P}<0.001$;

247 litter (GLM, d.f.=1, deviance=45.8, P=0.59; Fig. 2). The effect of fungal family $\times$

248 litter type interaction was not significant (GLM, d.f.=3, deviance=239.8, P=0.68).

249 In CT tests, the mass loss of AUR was significantly larger for Marasmiaceae than

250 for Mycenaceae and Tricholomataceae (GLM, d.f.=3, deviance $=5584.1, \mathrm{P}<0.001$;

251 Table 1) and was not significantly different among four litter types (GLM, d.f.=3,

252 deviance=83.7, $\mathrm{P}=0.94$; Fig. 2). The effect of fungal family $\times$ litter type interaction

253 was not significant (GLM, d.f. $=7$, deviance $=640.6, \mathrm{P}=0.91$ ). When analyzed

254 separately, however, the mean mass loss of AUR caused by CT isolates was

255 significantly lower in Fagus (lower) than in Fagus (upper) litter (paired t-test, 
256 d.f.=14, $\mathrm{t}=2.15, \mathrm{P}<0.05)$, suggesting that the higher initial $\mathrm{N}$ level in the lower

257 litter suppressed fungal decomposition of AUR. Specifically, this reduction was

258 attributed to the isolates of Mycenaceae, as the mean mass loss of AUR caused by

259 six isolates of Mycenaceae was significantly lower in the lower litter than in the

260 upper litter (paired t-test, d.f. $=5, \mathrm{t}=2.65, \mathrm{P}<0.05$ ). In contrast, no significant

261 difference was found for the AUR mass loss between the upper and lower litter

262 inoculated with six isolates of Marasmiaceae (paired t-test, d.f.=5, $t=1.06$,

$263 \mathrm{P}=0.337)$. In $\mathrm{SA}$ tests, the mass loss of AUR in Betula was not significantly

264 different among fungal families (GLM, d.f.=4, deviance=2612.1, P=0.07; Table 1).

265

266 Degree of selective decomposition of AUR

267

268 The mean AUR/L loss ratio for ST isolates ranged from 0.04 to 3.17 for

269 Castanopsis litter and from 0.04 to 2.21 for Schima litter; that for CT isolates

270 ranged from 1.33 to 3.70 for Fagus (upper) litter, from 0.93 to 3.17 for Fagus

271 (lower) litter, from 1.00 to 2.00 for Quercus litter, and from 1.39 to 2.57 for partly 
273 litter (Fig. 2).

274 In ST tests, AUR/L loss ratio was significantly different among fungal

275 families (GLM, d.f.=3, deviance=11.7, $\mathrm{P}<0.001$; Table 1) and was not significantly

276 different between Castanopsis and Schima litter (GLM, d.f.=1, deviance=0.02,

$277 \mathrm{P}=0.75 ;$ Fig. 3). That is, AUR/L loss ratio was significantly larger for

278 Marasmiaceae than for Mycenaceae and was significantly lower for Xylariaceae

279 than for Marasmiaceae and Mycenaceae. The effect of fungal family $\times$ litter type

280 interaction was not significant (GLM, d.f. $=3$, deviance $=0.52, \mathrm{P}=0.50)$. In $\mathrm{CT}$ tests,

281 AUR/L loss ratio was significantly larger for Marasmiaceae than for Mycenaceae

282 (GLM, d.f.=3, deviance=4.2, $\mathrm{P}<0.001$; Table 1) and was significantly larger in

283 Fagus (upper) and partly decomposed material than in Quercus litter (GLM,

284 d.f. $=3$, deviance=3.4, $\mathrm{P}<0.01$; Fig. 3). The effect of fungal family $\times$ litter type

285 interaction was not significant (GLM, d.f.=7, deviance=1.04, P=0.77). When

286 analyzed separately, the mean AUR/L loss ratio for CT isolates was significantly

287 lower in Fagus (lower) than in Fagus (upper) litter (paired t-test, d.f.=14, t=2.45,

$288 \mathrm{P}<0.05$ ), indicating that the higher initial $\mathrm{N}$ level in the lower litter reduced the

289 degree of selective decomposition of AUR. In SA tests, AUR/L loss ratio in Betula 
290 was significantly larger for Mycenaceae than for Tricholomataceae (GLM, d.f.=4,

291 deviance=2.7, $\mathrm{P}<0.001$; Table 1).

292

293 Discussion

294

295 Decomposing ability of litter

296

297 The mass loss values of litter-decomposing macrofungi (LDM) in the present

298 study (Fig. 1) are within the range in previous reports of pure culture

299 decomposition by basidiomycetes (Miyamoto et al. 2000; Boberg et al. 2011;

300 Žifčáková et al. 2011) and by xylariaceous Ascomycetes (Osono et al. 2011b). The

301 results also demonstrated the stronger decomposition of litter and

302 acid-unhydrolyzable residues (AUR) by LDM than non-ligninolytic microfungi on

303 leaf litter of subtropical and tropical (Osono et al. 2008, 2009), temperate (Osono

304 and Takeda 2002; Osono et al. 2003; Koide et al. 2005; Osono et al. 2006), and

305 subalpine forests (Osono and Takeda 2006). The negligible mass loss values of

306 Abies needles caused by SA isolates are possibly attributable to essential oils in 
307 needles that can inhibit fungal growth (Bağci and Diğrak 1996).

308

309 Fungal taxa and the decomposition of recalcitrant compounds

310

311 Decomposing activity for AUR was found in many macrofungal isolates in the

312 three sites (Figs 2 and 3), and has previously been primarily attributed to the

313 production of extracellular ligninolytic enzymes (Steffen et al. 2007; Valášková et

314 al. 2007). My data indicated that the isolates of Marasmiaceae were generally

315 better able to cause selective decomposition of AUR than those of Mycenaceae

316 (Table 1), although there was a degree of variation among the isolates. The ability

317 of Marasmiaceae to decompose AUR from partly decomposed material in CT tests

318 appeared unique as it contrasted with the abilities of Mycenaceae, which

319 exhibited reduced mass loss in partly decomposed material compared to freshly

320 fallen leaves of Fagus and Quercus (Table 1). This suggested that species in

321 Marasmiaceae are physiologically adapted to the partly decomposed materials

322 enriched in AUR, as proposed by Osono et al. (2011a). The isolates of Xylariaceae

323 in ST tests had lower ligninolytic activity than Basidiomycetes and caused 
324 selective decomposition of components other than AUR (Table 2), in accordance

325 with previous findings that xylariaceous fungi prefer cellulose to lignin (Nilsson

326 and Daniel 1989). Fukasawa et al. (2009) also showed that the production by

327 Xylaria species of pseudosclerotinial plates, which are insoluble to hot acid and

328 registered as AUR, could lead to a net increase of AUR (i.e., an apparent decrease

329 in mass loss of AUR) during pure culture decomposition.

330

331 Effect of litter quality

333 In CT tests, the mean value of AUR mass loss was lower in N-rich Fagus (lower)

334 litter than in N-poor Fagus (upper) litter (Fig. 2, Table 1), suggesting a retarding

335 effect of $\mathrm{N}$ on AUR decomposition. The lack of significant changes in the mass loss

336 of whole litter (Fig. 1) indicated the enhanced decomposition of other organic

337 components (possibly polymer carbohydrates, such as cellulose; Osono and Takeda

338 2001) than AUR. Such a retarding effect of $\mathrm{N}$ seemed more obvious for the isolates

339 of Mycenaceae than for those of Marasmiaceae (Table 1), supporting my previous

340 discussion that the ligninolytic system of Mycenaceae appears to be more 
341 sensitive to litter quality (i.e. the content of AUR and N) than that of

342 Marasmiaceae. Laboratory experiments documented the suppression of

343 ligninolytic enzyme activities produced by basidiomycetes due to $\mathrm{N}$ amendments

344 (Fenn et al. 1981; Reid 1991). Similarly, excess N supply often suppressed the

345 decomposition of recalcitrant components, such as lignin, in the field (Berg and

346 Laskowski 2006; Hagiwara et al. 2012), and the activity of ligninolytic enzymes in

347 soil (Sinsabaugh et al. 2005).

348

349 Comparison of macrofungi originated from different climates

351 Overall, the decomposing ability for leaf litter was similar at the level of

352 macrofungal assemblage among the three study sites. This appeared

353 contradictory to the hypothesis that the decomposition of AUR in leaf litter is

354 more active in warmer than in cooler climates. This discrepancy may be explained

355 by differences in the assemblage composition of LDM, in the soil layer which LDM

356 colonized, and in temperature. First, the richness and frequency of occurrence of

357 Mycenaceae were similar among the three sites, whereas those of Marasmiaceae, 
358 which included active decomposers of AUR (Table 1), were higher at warmer than

359 at cooler sites (Osono 2014b). The relative dominance of ligninolytic fungi in

360 Marasmiaceae in the macrofungal assemblage at warmer sites may be associated

361 with the more active decomposition of recalcitrant compounds in warmer than in

362 cooler climates. This is not contradictory with the finding of Osono (2011) that

363 non-ligninolytic microfungi in Ascomycetes were more frequent in surface litter at

364 cooler sites.

surface L layer in ST, whereas they mainly colonized the deeper layers in CT and

SA (Osono 2014b). The present study demonstrated that AUR decomposition by major macrofungal species in Mycenaceae was suppressed when such species

369 were inoculated to partly decomposed materials from F layer, compared to freshly

370 fallen leaves (Table 1), potentially leading to the retarded decomposition of

371 recalcitrant compounds in cooler climates. Thirdly, the higher temperatures in

372 warmer climates can enhance AUR decomposition by some ligninolytic fungi

373 (Adaskaveg et al. 1995; Osono et al. 2011c). However, how the decomposition of

374 AUR by LDM used in the present study responds to temperature and to what 
375 extent the temperature-dependent response varies among the LDM isolates of

376 different origins remain unclear and should be examined in the future.

378 Conclusion

380 The pure culture decomposition tests in the present study demonstrated that

381 LDM included isolates that were capable of decomposing litter actively and

382 removing recalcitrant compounds selectively. An array of LDM thus play major

383 roles in decomposition processes and nutrient recycling on the forest floor and are

384 probably major determinants of forest productivity and matter cycling within

385 forest ecosystems of the study sites. Litter-decomposing macrofungi originated

386 from forests of different climatic regions exhibited similar decomposing abilities,

387 but the decomposing ability of LDM varied with their taxonomic position (at the

388 family level) and the type of substrate (i.e., tree species, nutrient level, and the

389 degree of decomposition). In most cases, the effect of fungal family was more

390 significant than that of litter type, suggesting that possible changes in the

391 composition of LDM assemblages influence the functioning of LDM on the forest 
392 floor more than possible changes in the quality of substrates. This result is in

393 accordance with the finding of Osono (2014c) and emphasizes that studying the

394 species composition of fungal assemblages and decomposing abilities of individual

395 fungal species is crucial for predicting the response of fungal decomposition to

396 possible climate changes.

397

398 Acknowledgments

I thank Ms. K. Koide for help with pure culture tests;

399 and Dr. Elizabeth Nakajima for critical reading of the manuscript. This study

400 received partial financial support from the Ministry of Education, Culture, Sports,

401 Science, and Technology of Japan (MEXT) (No. 19780114), National Institute of

402 Agrobiologial Sciences (NIAS) Japan, The Sumitomo Foundation, Nissan Global

403 Foundation, Nippon Life Inst. Foundation, and the Grants for Excellent Graduate

404 Schools, MEXT, Japan (12-01) to Kyoto University.

405

406 References

408 Adaskaveg JE, Gilbertson RL, Dunlap MR (1995) Effects of incubation time and 
411 Bağci E, Diğrak M (1996) Antimicrobial activity of essential oils of some Abies (Fir) species from Turkey. Flavour Fragr J 11:251-256

413 Berg B, Laskowski R (2006) Litter decomposition: a guide to carbon and nutrient turnover. Amsterdam: Academic Press

Boberg JB, Ihrmark K, Lindahl BD (2011) Decomposing capacity of fungi commonly detected in Pinus sylvestris needle litter. Fungal Ecol $4: 110-114$

418 Fenn P, Choi S, Kirk TK (1981) Ligninolytic activity of Phanerochaete Arch Microbiol 130:66-71

Fukasawa Y, Osono T, Takeda H (2009) Effects of attack of saprobic fungi on twig chrysosporium: physiology of suppression by $\mathrm{NH} 4+$ and L-glutamate. plantations and adjacent secondary forests. J For Res 17:51-57 
426 Hirobe M, Sabang J, Bhatta BK, Takeda H (2004) Leaf-litter decomposition of 15

427

428

429

430

431

434

tree species in a lowland tropical rain forest in Sarawak: dynamics of carbon, nutrients, and organic constituents. J For Res 9:347-354

Imazeki R, Hongo T. 1987. Colored Illustration of Mushrroms of Japan. Vol. I. Hoikusha, Tokyo, Japan (in Japanese)

King HGC, Heath GW (1967) The chemical analysis of small samples of leaf material and the relationship between the disappearance and composition of leaves. Pedobiologia 7:192-197

Koide K, Osono T, Takeda H (2005) Fungal succession and decomposition of Camellia japonica leaf litter. Ecol Res 20:599-609

Lindahl B, Boberg J (2008) Distribution and function of litter basidiomycetes in coniferous forests. In: Boddy L, Frankland JC, van West P (eds) Ecology of Saprotrophic Basidiomycetes. Academic Press, London, pp. 183-196

Miura K, Kudo M (1970) An agar-medium for aquatic hyphomycetes. Trans Mycol Soc Japan 11:116-118 (in Japanese with English abstract)

Miyamoto T, Igarashi T, Takahashi K (2000) Lignin-degrading ability of litter-decomposing basidiomycetes from Picea forests of Hokkaido. 
444 Nilsson T, Daniel G (1989) Chemistry and microscopy of wood decay by some higher ascomycetes. Holzforschung 43:11-18

446 Osono T (2006) Fungal decomposition of lignin in leaf litter: comparison between tropical and temperate forests. In: Meyer W, Pearce C (eds) Proceedings for the 8th International Mycological Congress, August 20-25, 2006. Cairns, Australia. Medimond, Italy, pp. 111-117

Osono T (2007) Ecology of ligninolytic fungi associated with leaf litter decomposition. Ecol Res 22:955-974

Osono T (2011) Diversity and functioning of fungi associated with leaf litter decomposition in Asian forests of different climatic regions. Fungal Ecol temperate, and subalpine forests. J For Res 4:375-385

Osono T (2014a) Mycelial biomass in the forest floor and soil of subtropical, litter-decomposing macrofungi in subtropical, temperate, and subalpine forests. J For Res 
460 Osono T (2014c) Effects of litter type, origin of isolate, and temperature on decomposition of leaf litter by macrofungi. J For Res

462

Osono T, Takeda H (2001) Effects of organic chemical quality and mineral nitrogen addition on lignin and holocellulose decomposition of beech leaf litter by Xylaria sp. Eur J Soil Biol 37:17-23

465

Osono T, Takeda H (2002) Comparison of litter decomposing ability among diverse fungi in a cool temperate deciduous forest in Japan. Mycologia

Osono T, Fukasawa Y, Takeda H (2003) Roles of diverse fungi in larch needle litter decomposition. Mycologia 95:820-826

Osono T, Takeda H (2006) Fungal decomposition of Abies needle and Betula leaf litter. Mycologia 98: 172-179

Osono T, Hobara S, Koba K, Kameda K (2006) Reduction of fungal growth and lignin decomposition in needle litter by avian excreta. Soil Biol Biochem 38:1623-1630

475 Osono T, Ishii Y, Takeda H (2008) Fungal colonization and decomposition of 
477 Osono T, Hirose D (2009) Effects of prior decomposition of Camellia japonica leaf

478

479

480

484

485

486

litter by an endophytic fungus on the subsequent decomposition by fungal colonizers. Mycoscience 50:52-55

Osono T, Ishii Y, Takeda H, Seramethakun T, Khamyong S, To-Anun C, Hirose D, Tokumasu S, Kakishima M (2009) Fungal succession and lignin decomposition on Shorea obtusa leaves in a tropical seasonal forest in northern Thailand. Fungal Div 36:101-119

Osono T, Hirose D (2011) Colonization and lignin decomposition of pine needle litter by Lophodermium pinastri. For Path 41:156-162

Osono T, Hobara S, Hishinuma T, Azuma JI (2011a) Selective lignin decomposition and nitrogen mineralization in forest litter colonized by Clitocybe sp. Eur J Soil Biol 47:114-121

Osono T, To-Anun C, Hagiwara Y, Hirose D (2011b) Decomposition of wood, petiole and leaf litter by Xylaria species from northern Thailand. Fun Ecol $4: 210-218$

Osono T, Hagiwara Y, Masuya H (2011c) Effects of temperature and litter type on fungal growth and decomposition of leaf litter. Mycoscience 52:327-332 
494 Preston CM, Trofymow JA, Sayer BG, Niu J (1997) ${ }^{13}$ C nuclear magnetic

495

496

497

498

499

500 Sinsabaugh RL, Gallo ME, Lauber C, Waldrop MP, Zak DR (2005) Extracellular

501

502

503

504 Steffen KT, Cajthaml T, Šnajdr J, Baldrian P (2007) Differential degradation of 505

506 Res Microbiol 158:447-455

507 Tateno R, Takeda H (2010) Nitrogen uptake and nitrogen use efficiency above and

508

509 Oecol 163:793-804

510 Valášková V, Šnajdr J, Bittner B, Cajthaml T, Merhautová V, Hofrichter M, 

degradation of leaf litter by saprotrophic basidiomycetes isolated from a

514 Van der Wal A, Geydan TD, Kuyper TW, de Boer W (2013) A thready affair:

515 linking fungal diversity and community dynamics to terrestrial decomposition processes. FEMS Microbiol Rev 37:477-494

517 Žifčáková L, Dobiášová P, Kolářová Z, Koukol O, Baldrian P (2011) Enzyme 
Osono Table 1

Table 1. Mass loss (\% original mass) of litter and AUR and AUR/litter mass (AUR/L) loss ratio caused in vitro by isolates of macrofungi from subtropical (ST), cool temperate (CT), and subalpine forests (SA) at $20^{\circ} \mathrm{C}$ for 12 weeks in darkness. Fungal isolates were inoculated to litter collected from the respective forest sites. Values are means \pm standard errors for individual fungal families. Numbers of fungal isolates examined are indicated in parentheses. Nd, not determined. My, Mycenaceae; Mr, Marasmiaceae; Tr, Tricholomataceae; Hg, Hygrophoraceae; Hm, Hymenogasteraceae; Xy, Xylariaceae; Un, unidentified.

\begin{tabular}{|c|c|c|c|c|c|c|c|c|c|c|c|c|c|c|c|c|}
\hline & $\mathrm{ST}$ & & & & $\mathrm{CT}$ & & & & & & & & SA & & & \\
\hline Mass & ss\% & & & & & & & & & & & & & & & \\
\hline My & $18.0 \pm 2.9$ & (15) & $14.3 \pm 2.9$ & (15) & $18.2 \pm 3.2$ & (6) & $19.0 \pm 3.2$ & (6) & $22.6 \pm 5.1$ & (6) & $5.2 \pm 1.2$ & (6) & $-1.2 \pm 0.3$ & (10) & $26.7 \pm 4.3$ & (10) \\
\hline $\operatorname{Tr}$ & nd & & nd & & 14.2 & (2) & 14.1 & $(2)$ & 1.6 & (2) & 7.3 & (2) & $-0.5 \pm 0.3$ & (5) & $11.7 \pm 7.0$ & (5) \\
\hline $\mathrm{Hg}$ & nd & & nd & & 10.5 & (1) & 11.0 & (1) & 1.4 & (1) & 13.8 & (1) & nd & & nd & \\
\hline $\mathrm{Hm}$ & nd & & nd & & nd & & nd & & nd & & nd & & $-0.7 \pm 0.5$ & (4) & $4.0 \pm 2.9$ & (4) \\
\hline $\mathrm{Xy}$ & $10.3 \pm 2.6$ & (4) & $13.3 \pm 3.6$ & (4) & nd & & nd & & nd & & nd & & nd & & nd & \\
\hline
\end{tabular}




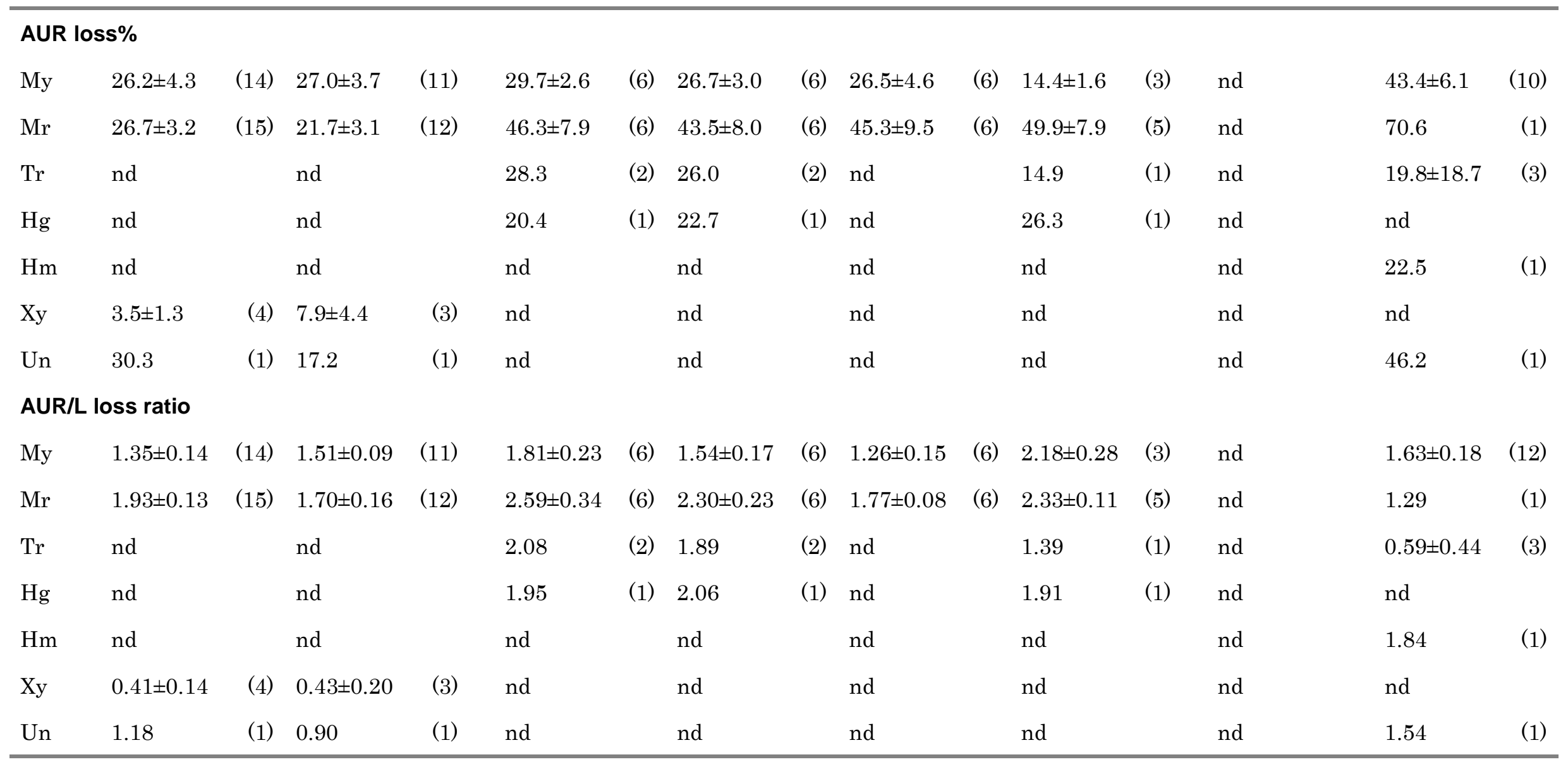


1 Figure legends

2

3 Fig. 1. Mass loss of leaf litter caused by multiple macrofungal isolates. Note that

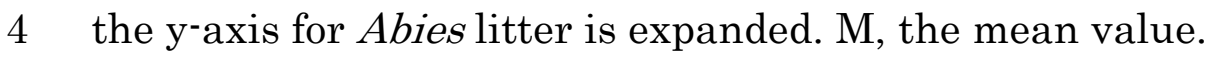

5

6 Fig. 2. Mass loss of acid unhydrolyzable residue (AUR) caused by multiple

7 macrofungal isolates.

8

9 Fig. 3. Acid unhydrolyzable residue-litter loss ratio (AUR/L) of multiple

10 macrofungal isolates.

11 
1 Osono Fig. 1

2
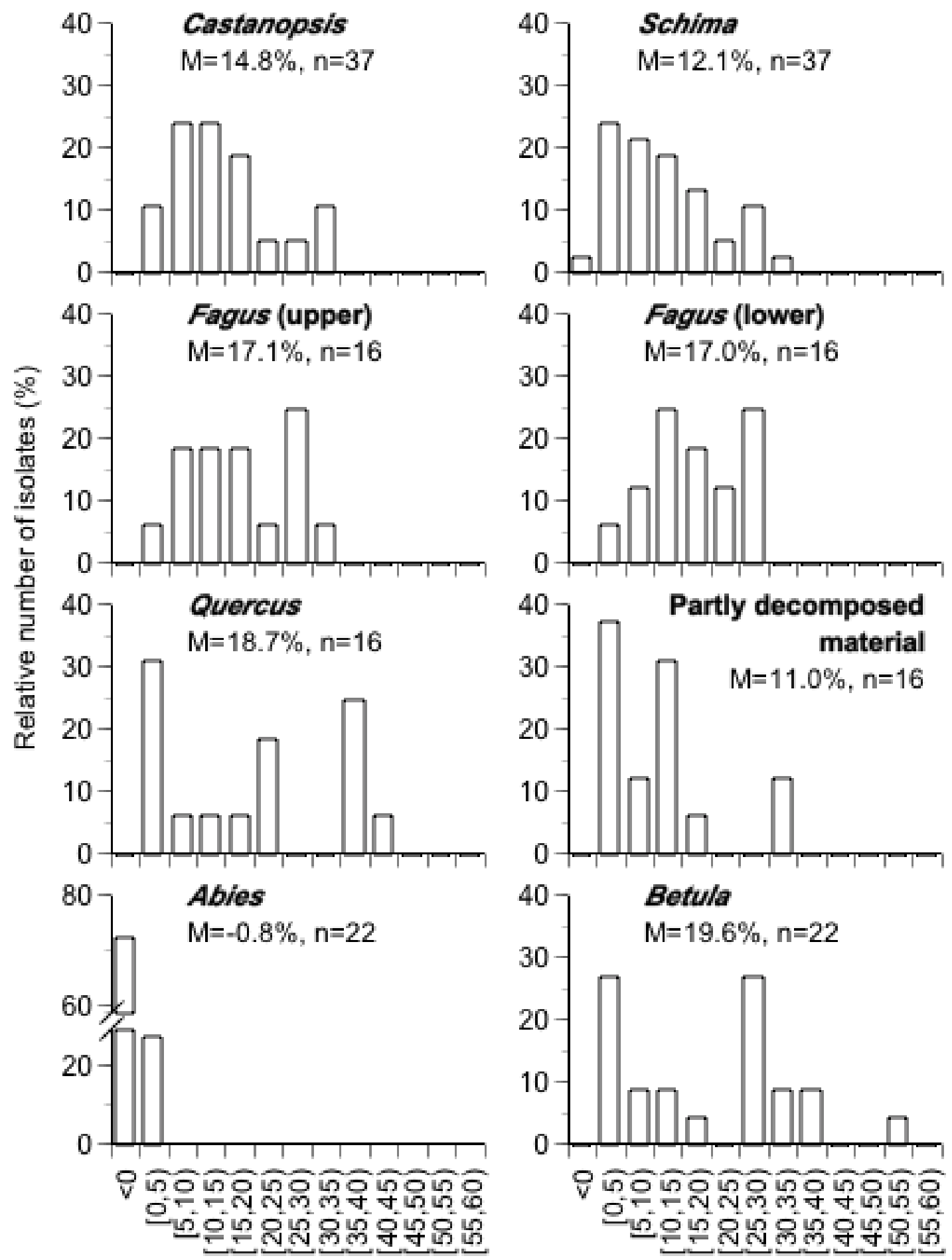

Mass loss of litter ( $\%$ original mass) 
1 Osono Fig. 2

2

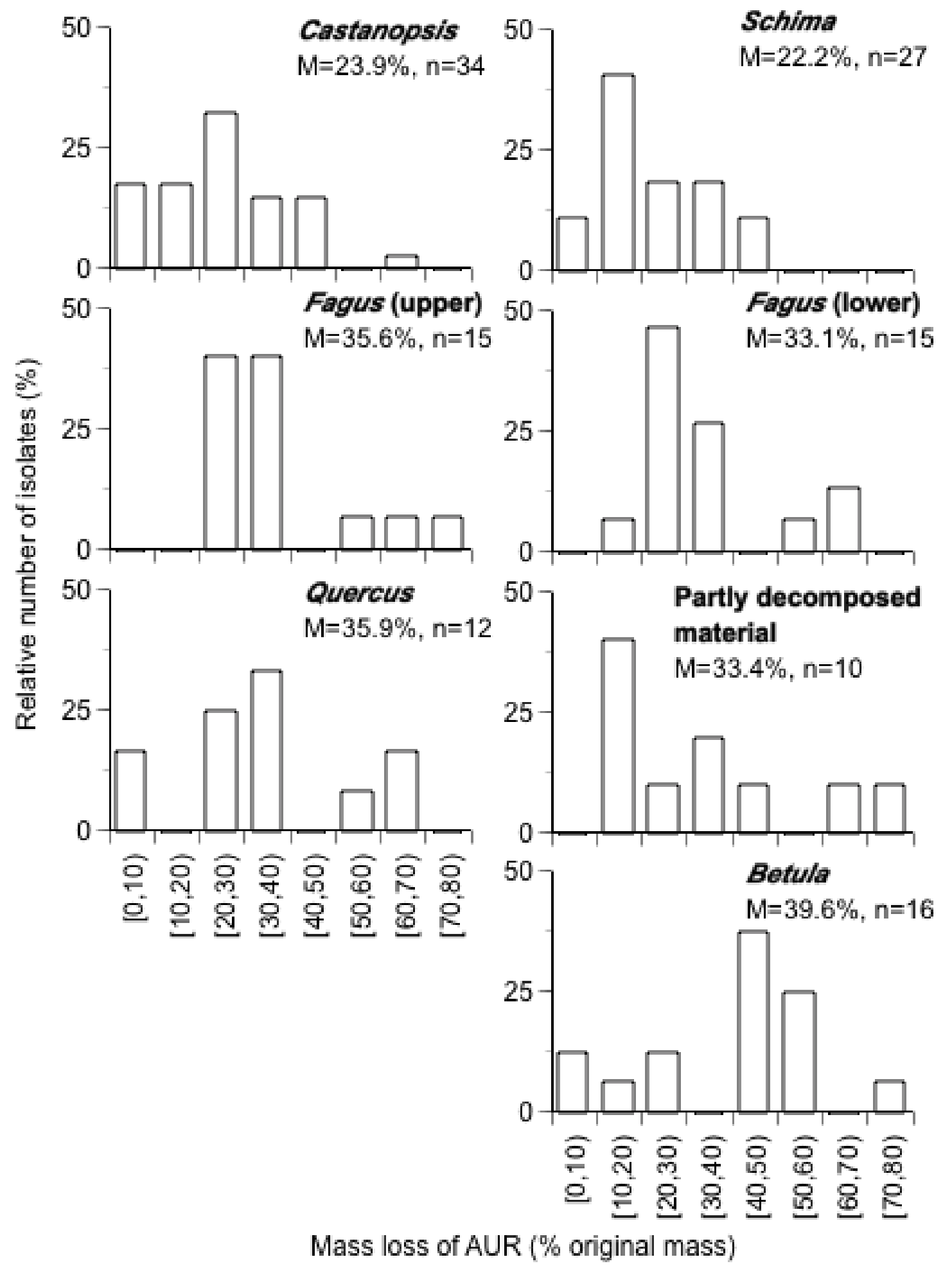


1 Osono Fig. 3

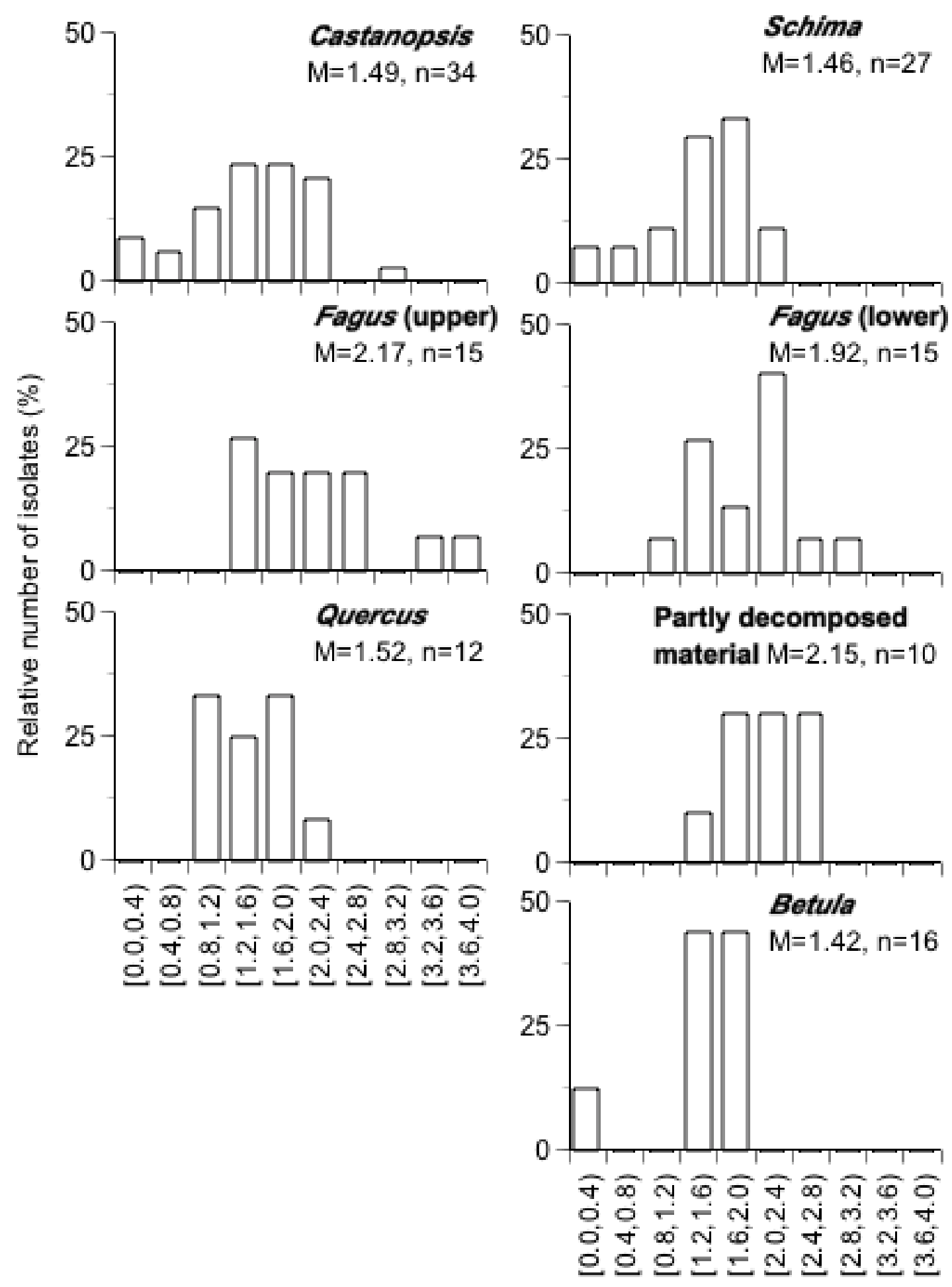

AUR/L loss ratio 


\section{Electronic Supplementary Material}

Decomposing ability of diverse litter-decomposer macrofungi in subtropical, temperate, and subalpine forests

Takashi Osono

S1: Mass loss (\% original mass) of litter and AUR, and AUR/litter mass loss ratio (AUR/L) caused by isolates of macrofungi from subtropical (ST), cool temperate (CT), and subalpine forests (SA) at $20^{\circ} \mathrm{C}$ for 12 weeks in darkness. Values indicate means \pm standard errors (n=4). Hy, Hygrophoraceae; Hm, Hymenogasteraceae; Mr, Marasmiaceae; My, Mycenaceae; Tr, Tricholomataceae; Xy, Xylariaceae; and Un, unidentified. nd, not determined.

\begin{tabular}{|c|c|c|c|c|c|c|c|c|}
\hline Таха & Accession & Family & $\begin{array}{l}\text { Mass loss of } \\
\text { litter }\end{array}$ & $\begin{array}{l}\text { Mass loss } \\
\text { of AUR }\end{array}$ & AUR/L & $\begin{array}{l}\text { Mass loss of } \\
\text { litter }\end{array}$ & $\begin{array}{l}\text { Mass loss } \\
\text { of AUR }\end{array}$ & AUR/L \\
\hline Subtropical forest & & & Castanopsis & & & Schima & & \\
\hline Mycena sp. ST6 & MAFF241594 & My & $34.2 \pm 4.4$ & 40.6 & 1.19 & $28.1 \pm 1.9$ & 33.1 & 1.18 \\
\hline Mycena sp. ST1 & MAFF241586 & My & $31.5 \pm 2.2$ & 44.8 & 1.42 & $26.7 \pm 3.1$ & 37.4 & 1.40 \\
\hline Mycena sp. ST2 & MAFF241589 & My & $28.8 \pm 2.0$ & 49.2 & 1.71 & $26.1 \pm 2.9$ & 41.0 & 1.57 \\
\hline Unidentified ST1 & MAFF241593 & Un & $25.7 \pm 3.4$ & 30.3 & 1.18 & $19.0 \pm 1.2$ & 17.2 & 0.90 \\
\hline
\end{tabular}




\begin{tabular}{|c|c|c|c|c|c|c|c|c|}
\hline Mycena sp. ST2 & MAFF241596 & My & $21.9 \pm 1.9$ & 29.6 & 1.35 & $16.3 \pm 3.6$ & 18.0 & 1.10 \\
\hline Gymnopus sp. ST3 & MAFF241614 & $\mathrm{Mr}$ & $20.1 \pm 2.5$ & 26.9 & 1.34 & $9.9 \pm 1.5$ & 21.7 & 2.21 \\
\hline Marasmiellus sp. ST1 & MAFF241613 & $\mathrm{Mr}$ & $20.0 \pm 1.2$ & 33.0 & 1.65 & $19.9 \pm 1.6$ & 39.4 & 1.98 \\
\hline Mycena sp. ST11 & MAFF241595 & My & $19.3 \pm 1.9$ & 22.9 & 1.19 & $21.2 \pm 3.0$ & 30.6 & 1.44 \\
\hline Xylaria sp. ST1 & MAFF241629 & Xy & $17.7 \pm 2.3$ & 0.8 & 0.04 & $22.5 \pm 2.7$ & 15.8 & 0.70 \\
\hline Crinipellis sp. ST2 & MAFF241605 & $\mathrm{Mr}$ & $15.6 \pm 1.9$ & 28.1 & 1.80 & $12.3 \pm 1.8$ & 18.2 & 1.48 \\
\hline Mycena sp. ST1 & MAFF241606 & My & $15.1 \pm 2.8$ & 12.2 & 0.81 & $10.4 \pm 2.1$ & 13.3 & 1.27 \\
\hline Gymnopus sp. ST1 & MAFF241616 & $\mathrm{Mr}$ & $14.7 \pm 2.0$ & 31.5 & 2.15 & $12.8 \pm 2.8$ & 21.8 & 1.71 \\
\hline Gymnopus sp. ST4 & MAFF241609 & $\mathrm{Mr}$ & $14.0 \pm 0.9$ & 32.5 & 2.32 & $17.4 \pm 0.5$ & 37.6 & 2.16 \\
\hline Gymnopus sp. ST2 & MAFF241611 & $\mathrm{Mr}$ & $10.8 \pm 2.0$ & 24.5 & 2.27 & $4.2 \pm 0.7$ & nd & nd \\
\hline Marasmius sp. ST2 & MAFF241603 & $\mathrm{Mr}$ & $10.6 \pm 2.2$ & 19.1 & 1.79 & $6.2 \pm 0.7$ & 12.3 & 1.98 \\
\hline Marasmius sp. ST3 & MAFF241632 & $\mathrm{Mr}$ & $10.5 \pm 0.7$ & 21.9 & 2.07 & $7.7 \pm 1.2$ & 13.7 & 1.78 \\
\hline Mycena sp. ST8 & MAFF241592 & Мy & $10.4 \pm 2.3$ & 24.3 & 2.34 & $8.3 \pm 1.1$ & 15.9 & 1.93 \\
\hline Marasmius sp. ST2 & MAFF241602 & $\mathrm{Mr}$ & $10.0 \pm 1.3$ & 20.7 & 2.08 & $3.8 \pm 1.4$ & nd & nd \\
\hline Gymnopus sp. ST1 & MAFF241612 & $\mathrm{Mr}$ & $10.0 \pm 1.9$ & 14.3 & 1.44 & $2.4 \pm 0.3$ & nd & nd \\
\hline Xylaria sp. ST1 & MAFF241599 & Xy & $9.5 \pm 1.6$ & 6.9 & 0.73 & $13.3 \pm 1.0$ & 7.4 & 0.55 \\
\hline
\end{tabular}




\begin{tabular}{|c|c|c|c|c|c|c|c|c|}
\hline Xylaria sp. ST1 & MAFF241598 & $\mathrm{Xy}$ & $8.3 \pm 2.3$ & 4.1 & 0.50 & $12.4 \pm 1.3$ & 0.5 & 0.04 \\
\hline Mycena sp. ST5 & MAFF241627 & My & $8.0 \pm 1.9$ & 12.0 & 1.49 & $7.4 \pm 2.2$ & 15.2 & 2.06 \\
\hline Mycena sp. ST3 & MAFF241617 & My & $7.3 \pm 1.4$ & 0.7 & 0.09 & $2.3 \pm 1.0$ & nd & nd \\
\hline Mycena sp. ST7 & MAFF241628 & My & $7.0 \pm 2.0$ & 11.7 & 1.67 & $2.0 \pm 0.4$ & nd & nd \\
\hline Xylaria sp. ST1 & MAFF241600 & Xy & $5.7 \pm 0.8$ & 2.1 & 0.37 & $4.9 \pm 1.2$ & nd & nd \\
\hline Marasmius sp. ST1 & MAFF241587 & $\mathrm{Mr}$ & $4.3 \pm 1.1$ & nd & nd & $1.8 \pm 0.5$ & nd & nd \\
\hline cf. Calyptella sp. ST1 & Y42_07110217 & $\mathrm{Mr}$ & $3.0 \pm 0.9$ & nd & nd & $6.9 \pm 3.0$ & 1.0 & 0.14 \\
\hline Mycena sp. ST4 & MAFF241597 & My & $2.3 \pm 0.3$ & nd & nd & $-0.4 \pm 0.6$ & nd & nd \\
\hline Cool temperate forest & & & Fagus (upper) & & & Fagus (lower) & & \\
\hline Gymnopus dryophilus & NBRC100095 & $\mathrm{Mr}$ & $26.3 \pm 3.1$ & 63.7 & 2.42 & $25.2 \pm 2.1$ & 62.4 & 2.47 \\
\hline Gerronema nemorale & 24GN_010914 & $\mathrm{Mr}$ & $25.9 \pm 2.9$ & 37.9 & 1.46 & $16.0 \pm 1.9$ & 23.0 & 1.44 \\
\hline Rhodocollybia butyracea & 19CB_000522 & $\mathrm{Mr}$ & $24.3 \pm 2.4$ & 53.0 & 2.18 & $27.5 \pm 2.9$ & 55.1 & 2.00 \\
\hline Mycena rorida & 22MR_010903 & My & $18.4 \pm 0.4$ & 30.8 & 1.67 & $18.2 \pm 0.7$ & 31.2 & 1.71 \\
\hline Infundibulicybe gibba & NBRC100092 & $\operatorname{Tr}$ & $17.7 \pm 5.1$ & 30.1 & 1.70 & $16.5 \pm 3.6$ & 26.3 & 1.60 \\
\hline Mycena polygramma & IFO33011 & My & $16.4 \pm 4.4$ & 24.5 & 1.50 & $23.4 \pm 3.4$ & 21.9 & 0.93 \\
\hline Mycena crocata & 15MC_0110MC & My & $12.6 \pm 0.7$ & 29.7 & 2.36 & $11.6 \pm 0.5$ & 21.8 & 1.88 \\
\hline
\end{tabular}




\begin{tabular}{|c|c|c|c|c|c|c|c|c|}
\hline Pseudoclitocybe cyathiformis & 18PC_0109PC & $\operatorname{Tr}$ & $10.8 \pm 2.6$ & 26.5 & 2.47 & $11.7 \pm 1.1$ & 25.6 & 2.18 \\
\hline Gymnopus peronatus & NBRC100096 & $\mathrm{Mr}$ & $9.5 \pm 0.6$ & 32.7 & 3.44 & $10.6 \pm 0.3$ & 33.6 & 3.17 \\
\hline Mycena amicta & 16MA_0109MA & My & $7.8 \pm 0.5$ & 20.7 & 2.66 & $8.3 \pm 0.4$ & 17.2 & 2.08 \\
\hline Marasmius pulcherripes & 23MP_010929 & $\mathrm{Mr}$ & $5.4 \pm 0.9$ & 20.1 & 3.70 & $9.4 \pm 0.9$ & 21.9 & 2.33 \\
\hline Rhodocollybia butyracea & IFO30747 & $\mathrm{Mr}$ & $4.1 \pm 1.5$ & nd & nd & $2.3 \pm 1.0$ & nd & nd \\
\hline Gymnopus dryophilus & 20CD_020412 & $\mathrm{Mr}$ & $35.8 \pm 1.7$ & 69.4 & 1.94 & $31.0 \pm 0.8$ & 70.4 & 1.91 \\
\hline Mycena polygramma & 21MP_010929 & My & $38.7 \pm 2.6$ & 38.8 & 1.00 & $3.0 \pm 1.2$ & nd & 2.27 \\
\hline Mycena amygdalina & 17MA_0110MA & My & $35.2 \pm 2.4$ & 36.9 & 1.05 & $3.9 \pm 2.1$ & nd & nd \\
\hline Gymnopus dryophilus & NBRC100095 & $\mathrm{Mr}$ & $42.8 \pm 1.5$ & 65.4 & 1.53 & $34.1 \pm 2.0$ & 67.5 & 1.98 \\
\hline Infundibulicybe gibba & NBRC100092 & $\operatorname{Tr}$ & $3.0 \pm 0.6$ & nd & nd & $10.7 \pm 2.1$ & 14.9 & 2.36 \\
\hline Mycena polygramma & IFO33011 & My & $21.5 \pm 3.7$ & 22.1 & 1.03 & $2.9 \pm 1.3$ & nd & nd \\
\hline Mycena crocata & 15MC_0110MC & My & $12.6 \pm 0.9$ & 24.6 & 1.96 & $5.1 \pm 0.9$ & 13.0 & nd \\
\hline Pseudoclitocybe cyathiformis & 18PC_0109PC & $\operatorname{Tr}$ & $0.1 \pm 0.4$ & nd & nd & $3.9 \pm 1.9$ & nd & 2.55 \\
\hline Ampulloclitocybe clavipes & IFO30524 & Hy & $1.4 \pm 1.0$ & nd & nd & $13.8 \pm 3.3$ & 26.3 & 2.27 \\
\hline Gymnopus peronatus & NBRC100096 & $\mathrm{Mr}$ & $20.8 \pm 0.4$ & 38.4 & 1.84 & $14.0 \pm 0.8$ & 35.9 & nd \\
\hline Mycena amicta & 16MA_0109MA & My & $6.8 \pm 0.8$ & 7.6 & 1.12 & $5.4 \pm 0.3$ & 12.7 & 1.62 \\
\hline
\end{tabular}




\begin{tabular}{|c|c|c|c|c|c|c|c|c|}
\hline Marasmius pulcherripes & 23MP_010929 & $\mathrm{Mr}$ & $1.6 \pm 0.9$ & nd & nd & $3.7 \pm 1.0$ & nd & nd \\
\hline Subalpine forest & \multicolumn{4}{|c|}{ Abies } & \multicolumn{2}{|c|}{ Betula } & & \\
\hline Marasmius androsaceus & O14_08072204 & $\mathrm{Mr}$ & $0.6 \pm 0.7$ & nd & nd & $54.5 \pm 1.6$ & 70.6 & 1.29 \\
\hline Tricholomataceae sp. SA1 & O23_08100702 & $\operatorname{Tr}$ & $0.0 \pm 0.4$ & nd & nd & $39.4 \pm 2.8$ & 57.1 & 1.45 \\
\hline Mycena sp. SA3 & O20_08091705 & My & $-3.1 \pm 0.2$ & nd & nd & $37.3 \pm 1.9$ & 56.7 & 1.52 \\
\hline Mycena epipterygia & O9_07101508 & My & $-2.3 \pm 1.1$ & nd & nd & $30.9 \pm 2.2$ & 46.5 & 1.50 \\
\hline Unidentified SA1 & O17_08081203 & Un & $-0.5 \pm 0.5$ & nd & nd & $29.9 \pm 2.1$ & 46.2 & 1.54 \\
\hline Mycena epipterygia & O8_07101507b & My & $-2.2 \pm 0.2$ & nd & nd & $29.0 \pm 2.8$ & 52.5 & 1.81 \\
\hline Mycena epipterygia & O7_07101507a & My & $-0.3 \pm 0.1$ & nd & nd & $27.8 \pm 1.6$ & 44.5 & 1.60 \\
\hline Mycena aurantiidisca & O1_07101503a & My & $0.0 \pm 0.2$ & nd & nd & $18.4 \pm 1.1$ & 29.7 & 1.62 \\
\hline Mycena cf. stipata & O25_08100703b & My & $-1.8 \pm 0.5$ & nd & nd & $12.2 \pm 4.9$ & 22.5 & 1.84 \\
\hline Galerina atkinsoniana & O15_08072207 & $\mathrm{Hm}$ & $-0.9 \pm 0.6$ & nd & nd & $12.0 \pm 1.9$ & 17.4 & 1.45 \\
\hline Tricholomataceae sp. SA1 & O10_07101509 & $\operatorname{Tr}$ & $-0.7 \pm 0.1$ & nd & nd & $7.8 \pm 1.1$ & 2.2 & 0.28 \\
\hline Tricholomataceae sp. SA1 & O19_08091702 & $\operatorname{Tr}$ & $-1.5 \pm 0.4$ & nd & nd & $6.4 \pm 1.7$ & 0.2 & 0.03 \\
\hline Mycena cf. pura & O3_07101504 & $\operatorname{Tr}$ & $0.3 \pm 0.2$ & nd & nd & $4.6 \pm 1.1$ & nd & nd \\
\hline Clitocybe sp. SA1 & O16_08081201 & $\mathrm{Mr}$ & $-1.0 \pm 0.6$ & nd & nd & $3.8 \pm 1.6$ & nd & nd \\
\hline
\end{tabular}




\begin{tabular}{|c|c|c|c|c|c|c|c|c|}
\hline Galerina atkinsoniana & O5_07101505b & $\mathrm{Hm}$ & $0.1 \pm 0.4$ & nd & nd & $3.7 \pm 2.2$ & nd & nd \\
\hline Galerina atkinsoniana & O6_07101506 & $\mathrm{Hm}$ & $0.1 \pm 0.4$ & nd & nd & $0.3 \pm 0.7$ & nd & nd \\
\hline Galerina atkinsoniana & O4_07101505a & $\mathrm{Hm}$ & $-1.2 \pm 0.3$ & nd & nd & $0.0 \pm 0.6$ & nd & nd \\
\hline
\end{tabular}

